\title{
DOES OECEOCLADES MACULATA (ORCHIDACEAE) REABSORB NECTAR?
}

\author{
JOÃO MARCELO ROBAZZI BIGNELLI VALENTE AGUIAR ${ }^{1, \star}$ and \\ EMERSON RICARDO PANSARIN ${ }^{2}$
}

\author{
${ }^{1}$ Programa de Pós-Graduação em Biologia Comparada, Departamento de Biologia, Faculdade de Filosofia, Ciências e Letras de \\ Ribeirão Preto, Universidade de São Paulo, Ribeirão Preto, Brazil \\ ${ }^{2}$ Departamento de Biologia, Faculdade de Filosofia, Ciências e Letras de Ribeirão Preto, Universidade de São Paulo, Ribeirão Preto, \\ Brazil \\ *Corresponding author: jmrobazzi@gmail.com
}

\begin{abstract}
Nectar is the most common resource offered by orchid flowers. In some cases, flowers reabsorb nectar as part of a resource-recovery strategy. Nectar is present only in the morning in the widespread orchid Oececoclades maculata (Lindl.) Lindl. To determine whether this is due to reabsorption or evaporation of water, the volume of nectar and its concentration in previously bagged flowers were determined throughout the day at two hourly intervals. In addition, the entrance to the nectary of flowers of cultivated plants was obstructed with petroleum jelly in the morning, to prevent the evaporation of water and, in the afternoon, the presence of nectar was recorded. Furthermore, manually self-pollinated flowers, also with the entrance to the nectary obstructed, had their nectary checked 24 hours after pollination to determine whether post-pollination reabsorption occurred. In addition, the period when the pollinators of $O$. maculata foraged for nectar was determined in order to establish whether it was associated with the period when nectar was available. The volume and concentration of nectar in O. maculata flowers vary from $0.82 \mu \mathrm{l}(25.10 \%)$ between $10-12 \mathrm{~h}$ and $0.36 \mu \mathrm{l}(33.73 \%)$ between $16-18 \mathrm{~h}$ and this difference is caused by evaporation of water. Post-pollination reabsorption does not occur in this species. Pollinators forage most actively between 10-12 $\mathrm{h}$. Thus, O. maculata does not reabsorb nectar, but evaporative water loss is a significant factor determining the variation in the volume and concentration of this reward and this is positively correlated with butterfly visitation.
\end{abstract}

Keywords: Epidendroideae; water evaporation; pollination; Heliconius; butterfly; nectar reabsorption

\section{Introduction}

Orchid flowers offer different floral resources to pollinators, such as oils, fragrance, pollen, edible trichomes and nectar (van der Pijl and Dodson 1966). Some species do not produce any kind of reward and, in those cases, the pollinators are deceived into visiting the flowers, a very common phenomenon among Orchidaceae (Ackerman 1986; Kindlmann and Roberts 2012). The most common resource offered by orchid flowers is nectar (van der Pijl and Dodson 1966; Arditti 1992; Dressler 1993), which can be produced in many different structures, including spurs (Neiland and Wilcock 1998). The presence of nectar can influence numerous aspects of pollinator behaviour, such as the number of flowers probed per plant and the probing duration, which affects the export and import of pollen (Jersáková and Johnson 2006; Jersáková et al. 2008). In fact, pollinators tend to make more and longer visits to flowers to which additional nectar has been added. However, this can result in higher levels of self-pollination, if it results in more flowers of the same plant being visited (Jersáková and Johnson 2006; Jersáková et al. 2008).

According to Galetto and Bernardello (2004), there is species-specific rhythmicity in nectar secretion and it is important to determine its dynamics throughout the lifespan of a flower in order to understand the plant-animal relationships. The nectar offering strategies of plants in terms of the activity patterns, frequency and diversity of pollinators cannot be understood without considering the dynamics of nectar production (Galetto and Bernardello 2004).

Some of the cases of nectar reabsorption documented for Orchidaceae (Koopowitz and Marchant 1998; Luyt and Johnson 2002) are attributed to saving energy, which the plant could use to invest in fruit development (Koopowitz and Marchant 1998). In these cases the flowers reabsorb nectar after pollination. A decrease in the volume of nectar accompanied by a decrease in sugar concentration indicates nectar reabsorption (Nepi and Stpiczyńska 2008).

Oeceoclades maculata (Lindl.) Lindl. (Orchidaceae: Epidendroideae: Cymbideae: Eulophiinae) is a widespread species that is pollinated by Heliconius butterflies, while obtaining the nectar in the spur at the base of the labellum (Aguiar et al. 2012). The nectar is present only in the morning, which indicates that it is probably reabsorbed by the afternoon (Aguiar et al. 2012).

Based on the above evidence, the main objective of this study is to determine whether nectar reabsorption occurs in flowers of a Brazilian population of Oeceoclades maculata, as previously suggested by Aguiar et al. (2012). Thus, the volume and concentration of sugar in the nec$\operatorname{tar}$ of $O$. maculata were recorded throughout the day and a nectar reabsorption experiment was done using petroleum jelly. Furthermore, the timing of nectar production was compared with when butterflies were active during the flowering period of $O$. maculata, to determine if there is positive relation between nectar availability and visits by pollinators. 


\section{Materials and methods}

\section{Study site}

Fieldwork was carried out on the campus of the São Paulo University (FFCLRP-USP), in the municipality of Ribeirão Preto (approximately $21^{\circ} 09^{\prime} \mathrm{S}, 47^{\circ} 51^{\prime} \mathrm{W}$ ), State of São Paulo, southeastern Brazil, during the flowering period of O. maculata in 2011 and 2012. The climate there is characterized as 'Cwa' (mesothermic with a dry winter) according to Köppen (1948). The summer is hot and rainy, with mean temperatures above $22{ }^{\circ} \mathrm{C}$ and average precipitation greater than $250 \mathrm{~mm}$. The winter is dry, with mean temperatures below $18^{\circ} \mathrm{C}$ and average precipitation less than $30 \mathrm{~mm}$ in the colder months. Most of this region is covered with mesophytic semideciduous forests. Our study was carried in a natural population located in an anthropogenically-disturbed area, underneath a closed canopy, at approximately $500 \mathrm{~m}$ a.s.l. The total area of the campus is approximately 450 ha, but the fieldwork was done in a six ha area in which there were approximately 250 adult individuals of Oeceoclades maculata.

\section{Study species}

Oeceoclades maculata (Orchidaceae: Epidendroideae: Cymbideae: Eulophiinae) is a widespread terrestrial species, occurring throughout Florida, Panama, West Indies, South America and tropical Africa. Plants are commonly found in disturbed areas of dry, moist and wet forests (Ackerman 1995). In Brazil, the species is widely distributed, occurring in many types of vegetation (E. R. Pansarin, pers. obs. 2010).

According to Pansarin and Pansarin (2010), this species characteristically has oval, laterally compressed and unifoliate pseudobulbs. The leaves are elliptical, green mottled with darker green, coriaceous and erect. The inflorescence is lateral and erect with up to 15 resupinate flowers. The flowers are predominantly pinkish, with sepals connivent with the petals. The labellum is threelobbed, with a spur at the base, pale-pink with two pink spots internally. Flowers are scentless to humans (Ackerman 1995). A voucher specimen (E. R. Pansarin and F. D. Galli 1280) is deposited in the herbarium of the Universidade de São Paulo (SPFR).

\section{Nectar reabsorption experiments}

In order to determine if the reabsorption of nectar in flowers of Oeceoclades maculata occurs throughout the day, 21 plants were used. The plants were previously collected in the field and maintained in the Orchidarium LBMBP on the campus of São Paulo University (FFCLRP-USP), in the municipality of Ribeirão Preto, State of São Paulo, southeastern Brazil. On each individual plant, three flowers were sampled. The nectar in the first flower was drained off by 10:00 $\mathrm{h}$ in order to confirm the plant was producing nectar. The entrance to the nectary of the second flower was obstructed with petroleum jelly at 10:00 $\mathrm{h}$ and the nectar removed by 17:00 $\mathrm{h}$.
The nectar produced by the third flower was measured at 17:00 $\mathrm{h}$ and acted as the control.

In addition, 20 plants previously collected and kept in the Orchidarium LBMBP were used to determine whether nectar reabsorption occurred after manual pollination of these plants. On each plant, three flowers were sampled. The nectar of the first flower was collected before 10:00 $\mathrm{h}$ to make sure the plant was producing nectar. The second flower was self-pollinated and the entrance to its nectary obstructed with petroleum jelly. The third flower was self-pollinated but the entrance to its nectary was not obstructed. The nectar in the second and third flowers was measured $24 \mathrm{~h}$ later.

The volume of nectar collected in all of the experiments was measured using a 10 microliter syringe (Hamilton, NV, USA) (Sazima et al. 2003).

\section{Nectar volume and concentration}

In order to determine when Oeceoclades maculata produced nectar, 40 inflorescences (40 plants) were previously enclosed in nylon bags in the field. Petroleum jelly was applied to the base of inflorescences to prevent insects from visiting the flowers. Flowers were collected at intervals of two hours: 6-8 h, 8-10 h, 10-12 h, 12-14 h, 14-16 $\mathrm{h}$ and 16-18 $\mathrm{h}$. In each interval, 30 flowers were sampled. 30 flowers from 10 plants were used to determine if flowers produced more nectar after it was removed.

Nectar volume and concentration were measured using a 10 microliter syringe (Hamilton, NV, USA) and a hand held refractometer (Eclipse, UK, 0-50\%), respectively (Sazima et al. 2003).

\section{Period of activity of pollinators}

The observations carried out to determine whether the period when the pollinators of Oeceoclades maculata (Heliconius ethilla narcaea (Godart 1819) and H. erato phyllis (Fabricius 1775; Aguiar et al. 2012)) were active were carried out over total period of $38 \mathrm{~h}$ in a natural habitat on sunny days during the flowering period in the 2011. Oeceoclades maculata flowers during summer, when on most of the days it rained at the study site in 2011, which made it impossible to sample systematically at selected intervals of the day, as described above. To correct for the effect of differential sampling, the total number of pollinator visits in each interval was divided by the number of times that the respective interval was sampled. Details of the observations are summarized in Table 1.

\section{Data analysis}

In order to determine if there is a linear dependence between nectar volume and concentration, a Pearson product-moment correlation coefficient was used. The same analysis was used to verify the existence of linear dependence between nectar volume and visits by pollinators. To determine the effect of time of day on nectar 
Table 1 Data on the periods when the visits by pollinators were recorded and the intervals during the course of the day when the volume of nectar volume was measured for the correlation analysis.

\begin{tabular}{|c|c|c|}
\hline Day & Period of observation & Intervals when volume of nectar was measured \\
\hline March 15, 2011 & $06: 00 \mathrm{~h}$ to $15: 00 \mathrm{~h}$ & 06-08h; 08-10h; $10-12 h ; 12-14 h ; 14-16 h$ \\
\hline March 16, 2011 & $06: 00 \mathrm{~h}$ to $15: 00 \mathrm{~h}$ & $06-08 h ; 08-10 h ; 10-12 h ; 12-14 h ; 14-16 h$ \\
\hline March 19, 2011 & $09: 00 \mathrm{~h}$ to $11: 00 \mathrm{~h}$ & $08-10 \mathrm{~h} ; 10-12 \mathrm{~h}$ \\
\hline March 27, 2011 & $09: 00 \mathrm{~h}$ to $18: 00 \mathrm{~h}$ & $08-10 h ; 10-12 h ; 12-14 h ; 14-16 h ; 16-18 h$ \\
\hline April 10, 2011 & $09: 00 \mathrm{~h}$ to $18: 00 \mathrm{~h}$ & $08-10 h ; 10-12 h ; 12-14 h ; 14-16 h ; 16-18 h$ \\
\hline
\end{tabular}

volume and concentration, one-way ANOVA tests were performed. The difference between the volume of nectar in the treated flowers and that in flowers from which the nectar was removed by 10:00 $\mathrm{h}$ in the nectar reabsorption experiments was tested for statistical significance using Student's $t$-tests. The data from the same experiments that were not normally distributed were analyzed using the Mann-Whitney $U$-test. IBM $^{\circ}$ SPSS ${ }^{\circ}$ version 21 was used to do the statistical analysis.

\section{Results}

\section{Reabsorption of nectar}

Nectar volume did not differ significantly between flowers that had nectar removed at 10:00 and those whose nectaries were sealed with petroleum jelly (Student's $t$-test; $\left.t_{40}=0.19, p>0.05\right)$. On the other hand, at $17: 00 \mathrm{~h}$ there was significantly less nectar in the flowers with the entrance to nectaries not obstructed (Mann-Whitney; $U=19.00, p<0.001$ ), with $81.00 \%$ of them containing no nectar at this time.

The self-pollinated flowers with obstructed nectaries did not differ significantly in nectar volume $24 \mathrm{~h}$ after pollination from those that had the nectar removed at
10:00 h (Student's $t$-test; $t_{38}=1.85, p>0.05$ ). In contrast, there was significantly less nectar $24 \mathrm{~h}$ after pollination in the self-pollinated flowers with no nectary obstruction (Mann-Whitney; $U=2.00, p<0.001$ ), with $80.00 \%$ of them containing no nectar.

This indicates that Oeceoclades maculata flowers do not reabsorb nectar either during the course of a day or after pollination and the decrease in volume is due to evaporation of water.

\section{Nectar volume and concentration}

The volume and concentration of nectar in flowers of Oeceoclades maculata varies throughout the day (Fig. 1). Between 10-12 h themean nectarvolume was $0.82 \pm 0.08 \mu \mathrm{l}$, (mean \pm SE) and between $16-18 \mathrm{~h}$ it was $0.36 \pm 0.5 \mu \mathrm{l}$. The concentration of sugar in the nectar was $33.73 \% \pm$ $0.62 \%$ (mean \pm SE) between $16-18 \mathrm{~h}$ and $25.10 \% \pm 0.84 \%$ between $10-12 \mathrm{~h}$. The Pearson correlation test revealed a strong negative correlation $(\rho=-0.8967)$ between the volume of nectar and its concentration. The ANOVA revealed that the time of day is a significant factor associated with the variation in volume $\left(F_{5,174}=7.25\right.$, $p<0.001)$ and concentration $\left(F_{5,174}=37.74, p<0.001\right)$ of nectar. Flowers did not produce more nectar after it was removed.

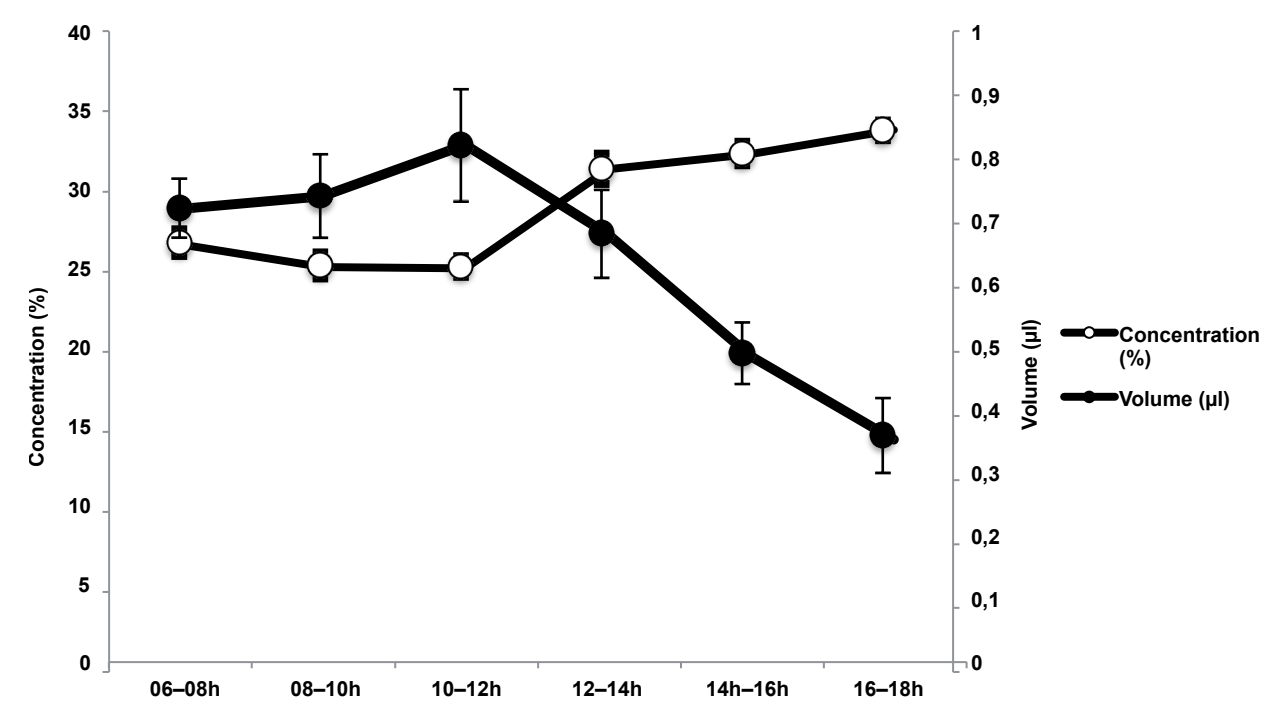

Fig. 1 Variation in volume and concentration (mean $\pm \mathrm{SE}, n=30$ ) of the nectar in flowers of Oeceoclades maculata. Note that after the 10-12 $\mathrm{h}$ period, the volume of nectar decreases and its concentration increases, indicating evaporation of water. 


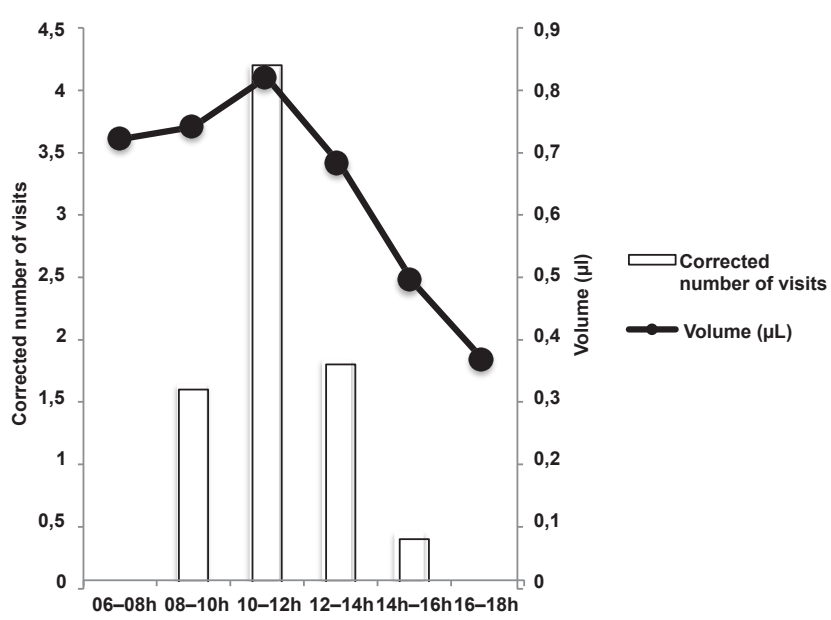

Fig. 2 Number of visits (total number of visits in an interval divided by the number of times that the respective interval was sampled) by both Heliconius ethilla narcaea and H. erato phyllis to flowers of Oeceoclades maculata throughout the course of a day and positive correlation between volume of nectar and the incidence of visits by the butterflies to flowers.

\section{Activity period of pollinators}

Pollinators of Oeceoclades maculata visit the flowers mainly in the morning, with visits occurring between 8:00 h and approximately 16:00 h (Fig. 2). No visits were recorded between 6-8 h and 16-18 h. The Pearson correlation test revealed that there is a moderate positive correlation $(\rho=0.69)$ between the visits of butterflies to flowers and nectar volume (Fig. 2).

\section{Discussion}

Floral nectar is the most commonly resource produced by orchids (van der Pijl and Dodson 1966; Arditti 1992; Dressler 1993) and its production is costly for plants (Koopowitz and Marchant 1998; Nepi and Stpiczyńska 2008). The flowers of some species can reabsorb nectar (Nicolson 1995; Koopowitz and Marchant 1998; Nepi et al. 2001; Luyt and Johnson 2002; Agostini et al. 2011; Stpiczyńska et al. 2012) and this is seen as part of a resource-recovery strategy and a means of maintaining homesostasis in the nectary. This phenomenon is characterized by a simultaneous decrease in volume and increase in concentration (Nepi and Stpiczyńska 2008).

According to Aguiar et al. (2012), in Brazil Oeceoclades maculata flowers produce small quantities of nectar, which is used as resource by Heliconius butterflies. They infer that by the afternoon the flowers of $\mathrm{O}$. maculata reabsorb the nectar.

The results obtained here show that at 6:00 h, when some flowers of Oeceoclades maculata are still opening, there is already nectar in the spur of the flower and the volume of nectar increases up to ca. 10:00 h, when each flower contains a mean volume of $0.81 \mu \mathrm{l}$. This indicates that the nectar is produced before the flowers open, as is documented for the orchid Cleistes libonii (Rchb.f.) Schltr. (as Cleistes macrantha (Barb. Rodr.) Schltr.; Pansarin
2003). The concentration of the nectar between 6:00 and 10:00 h remains constant whereas the volume increases, which indicates that nectar is being secreted. After 10:00 h the volume of nectar decreases throughout the day reaching a mean value of $0.36 \mu \mathrm{l}$ after 16:00 h.

The experiments on reabsorption revealed that the decrease in the volume of nectar is due not to reabsorption but evaporation. There was a significant decrease in the volume of nectar in the nectaries that were not obstructed with petroleum jelly whereas there was no meaningful variation in the volume of nectar in the flowers with the entrance to the nectaries obstructed, which indicates evaporation of water accounts for the decrease in volume. In addition, after 10:00 h, the volume of nectar in the flowers of O. maculata decreases, whereas its concentration increases.

Although nectar reabsorption can occur after pollination and is documented for other species of orchids (Koopowitz and Marchant 1998; Luyt and Johnson 2002), this did not occur in O. maculata. By obstructing the nectary of self-pollinated flowers we prevented the evaporation of water from the nectar via the nectary entrance and only in the non-treated flowers there was a significant decrease in the volume of nectar. So, it is plausible to affirm that evaporation also accounts for the absence of nectar in many flowers $24 \mathrm{~h}$ after pollination.

Most species of plants restrict the visits by pollinators to time-windows of nectar availability, by changing the quantity and quality of this resource (Linnaeus 1751; von Buttel-Reepen 1900). In the squash, Cucurbita pepo L., nectar volume and concentration varies significantly during the course of the day and this have influence on when honey bees visit its flowers (Edge et al. 2012). This also seems to be the case for O. maculata, in which nectar volume and concentration also varies throughout the day and there is a positive correlation between nectar volume and the frequency of visits by Heliconius butterflies. In Stachytarpheta cayennensis (Rich) Vahl (Verbenaceae) there is also a positive relation between nectar volume and visits by pollinators (Barp et al. 2011). Heliconius erato, a species also recorded as a pollinator of $O$. maculata (Aguiar et al. 2012), prefers to visit the flowers of S. cayennensis in the morning when they contain the maximum volume of nectar and the incidence of visits during the course of the day decrease as the volume of nectar in the flowers decreases (Barp et al. 2011). Butterflies were most active between 10:00 $\mathrm{h}$ and 12:00 $\mathrm{h}$ at our study site, which coincides with the period when the volume of nectar in the flowers of $O$. maculata was at its maximum.

Furthermore, Barp et al. (2011) show that Heliconius erato prefers nectar with a concentration of between $20-40 \%$, and this is similar to what we recorded in flowers of Oeceoclades maculata between 10:00 h and 12:00 h, when the flowers contained the greatest volume of nectar and were most visited by pollinators (25.10\%).

Although many studies indicate that the presence of nectar increases the levels of self-pollination, and thus 
inbreeding depression (Johnson et al. 2004; Jersáková and Johnson 2006; Jersáková et al. 2008), in O. maculata the presence of nectar is important for cross-pollination. If no resource is available, the number of visits by pollinators would be even lower and the flowers would then have to rely on self-pollination in order to reproduce. Autonomous self-pollination and nectar secretion occurs in the orchid Epipogium roseum (D. Don) Lindl. yet its flowers are visited by the Asian honeybee. However, E. roseum does not undergo outcrossing mediated by insects, because the bee cannot remove the pollinaria of flowers due to the absence of an adhesive viscidium. Thus, E. roseum is obligatorily self-pollinated (Zhou et al. 2012). In O. maculata, although the reproductive structures allow the occurrence of biotic cross-pollination, such as the presence of a functional viscidium, development of fruit depends mainly on autonomous self-pollination, but cross-pollination events also occur (Aguiar et al. 2012). Therefore, the nectar in O. maculata flowers has an important role in attracting pollinators and thereby maintaining the occurrence of some cross-pollination, unlike what happens in E. roseum.

In conclusion, we can affirm that the volume and concentration of nectar in the flowers of $O$. maculata varies throughout the day not as a consequence of nectar reabsorption, as inferred by Aguiar et al. (2012), but due to evaporation of water. This is variation is associated with the attraction of pollinators to flowers of O. macula$t a$, which visits the flowers mainly in the morning when the maximum volume of nectar is available. Although O. maculata do not depend on pollinators for fruit formation (González-Díaz and Ackerman 1988; Aguiar et al. 2012), the role of Heliconius butterflies in providing an opportunity for cross-pollination can, at least presumably, contribute to an increase in genetic variability when compared to strictly autogamous populations (Aguiar et al. 2012).

\section{Acknowledgements}

The authors thank F. H. M. de Souza and A. L. R. L. Vimbardi for help with measuring the concentration of the nectar, J. R. Barosela for help with data analysis and especially L. M. Pansarin for help in developing methods and discussing the results. J. M. R. B. V. Aguiar is a regular student on the Post-Graduation Program in Comparative Biology (FFCLRP-USP) and thanks the Fundação de Amparo à Pesquisa do Estado de São Paulo (FAPESP) for financial support (Grant 2011/02697-3).

\section{REFERENCES}

Ackerman JD (1986) Mechanisms and evolution of food deceptive pollination systems in orchids. Lindleyana 1: 108-113.

Ackerman JD (1995) An orchid flora of Puerto Rico and the Virgin Islands. The New York Botanical Garden, New York.
Agostini K, Sazima M, Galetto L (2011) Nectar production dynamics and sugar composition in two Mucuna species (Leguminosae, Faboidae) with different specialized pollinators. Naturwissenchaften. doi: 10.1007/s00114-011-0844-6.

Aguiar JMRBV, Pansarin LM, Ackerman JD, Pansarin, ER (2012) Biotic versus abiotic pollination in Oeceoclades maculata (Lindl.) Lindl. (Orchidaceae: Epidendroideae). Plant Spec Biol. doi: 10.1111/j.1442-1984.2011.00330.x.

Arditti J (1992) Fundamentals of orchid biology. John Wiley and Sons, New York.

Barp EA, Soares GLG, Giani EJM, Rodrigues D, Moreira GRP (2011) Variation in nectar and pollen availability, sucrose, preference, and daily response in the use of flowers by Heliconius erato phylis. J Insect Behav. doi: 10.1007/s10905-010-9248-2.

Dressler RL (1993) Phylogeny and classification of the orchid family. Cambridge University Press, Cambridge.

Edge AA, van Nest BN, Johnson JN, Miller SN, Naeger N, Boyd SD, Moore D (2012) Diel nectar secretion rhythm in squash (Cucurbita pepo) and its relation with pollinator activity. Apidologie. doi: 10.1007/s13592-011-0087-8.

Galetto L, Bernardello G (2004) Floral nectaries, nectar production dynamics and chemical composition in six Ipomoea species (Convolvulaceae) in relation to pollinators. Ann Bot. doi: 10.1093/aob/mch137.

Gonzalez-Díaz N, Ackerman JD (1988) Pollination, fruit set, and seed production in the orchid Oeceoclades maculata. Lindleyana 3: 150-155.

Jersáková J, Johnson SD (2006) Lack of floral nectar reduces self-pollination in a fly-pollinated orchid. Oecologia. doi: 10.1007/s00442-005-0254-6.

Jersáková J, Johnson SD, Kindlmann P, Pupin AC (2008) Effect of nectar supplementation on male and female components of pollination success in the deceptive orchid Dactylorhiza sambucina. Acta Oecol. doi: 10.1016/j.actao.2008.01.001.

Johnson SD, Peter CI, Agren J (2004) The effects of nectar addition on pollen removal and geitonogamy in the non-rewarding orchid Anacamptis morio. P R Soc B. doi: 10.1098/rspb.2003.2659.

Kindlmann P, Roberts DL (2012) When is an asymmetric plant-pollinator relationship symmetrical? Eur J Environ Sci 2: 15-18.

Koopowitz H, Marchant TA (1998) Postpollination nectar reabsorption in the African epiphyte Aerangis verdickii (Orchidaceae). Am J Bot 85: 508-512.

Köppen W (1948) Climatologia. Fondo de Cultura e Economia, Mexico.

Linnaeus C (1751) Philosophia Botanica, 1st edn. Kiesewetter, Stockholm.

Luyt R, Johnson SD (2002) Postpollination nectar reabsorption and its implications for fruit quality in an epiphytic orchid. Biotropica. doi: 10.1111/j.1744-7429.2002.tb.00558.x.

Neiland MRM, Wilcock CC (1998) Fruit set, nectar reward, and rarity in the Orchidaceae. Am J Bot 85: 1657-1671.

Nepi M, Stpiczyńska M (2008) The complexity of nectar: secretion and reabsorption dynamically regulate nectar features. Naturwissenschaften. doi: 10.1007/s00114-007-0307-2.

Nicolson SW (1995) Direct demonstration of nectar reabsorption in the flowers of Grevillea robusta (Proteaceae). Funct Ecol 9: $584-588$.

Pansarin ER (2003) Biologia floral de Cleistes macrantha (Barb. Rodr.) Schltr. (Orchidaceae: Vanilloideae: Pogoniinae). Rev Bras Bot 26: 73-80.

Pansarin ER, Pansarin LM (2010) The family Orchidaceae in the Serra do Japi, São Paulo State, Brazil. Springer Wien New York, Viena. 
Sazima M, Buzato S, Sazima I (2003) Dyssochroma viridiflorum (Solanaceae): a reproductively bat-dependent epiphyte from the Atlantic Rainforest in Brazil. Ann Bot. doi: 10.1093/aob/mcg190. Stpiczyńska M, Nepi M, Zych M (2012) Secretion and composition of nectar and the ultrastructure of perigonal nectaries in Fritillaria meleagris L. (Liliaceae). Plant Syst Evol. doi: 10.1007 /s00606-012-0609-5. van der Pijl L, Dodson, CH (1966) Orchid flowers, their pollination and evolution. University of Miami Press, Florida.

von Buttel-Reepen HB (1900) Sind die Bienen Reflexmaschinen? Biol Zbl 20: 1-82.

Zhou X, Lin H, Fan X-L, Gao J-Y (2012) Autonomous self-pollination and insect visitation in a saprophytic orchid, Epipogium roseum (D. Don) Lindl. Aust J Bot. doi: 10.1071/BT11265. 